\title{
Factors Motivating Use of Digital Libraries
}

\author{
Flora McMartin \\ Broad Based Knowledge \\ 5935 Orchard Ave \\ Richmond, CA 94804 \\ +1- 510-967-5327 \\ flora.mcmartin@gmail.com
}

\author{
Ellen Iverson \& Cathryn \\ Manduca \\ Carleton College \\ Science Education Resource Center \\ +1-507-646-5749 \\ eiverson@carleton.edu
}

\author{
Alan Wolf \\ University of Wisconsin \\ alanwolf@wisc.edu \\ Glenda Morgan \\ CSU, Office of the Chancellor \\ gmorgan@calstate.edu
}

\begin{abstract}
Knowledge about how users use digital libraries and their contents is inextricably tied to a library's ability to sustain itself, grow its services and meet the needs of its users. This paper reports on the preliminary results of a study of how science, technology, engineering and mathematics (STEM) instructors perceive and use digital libraries. Preliminary findings indicate that: they do not differentiate between digital libraries and other kinds of content that comes from the web, they seek content to supplement traditional teaching methods and their reliance on Google and personal networks impedes their ability to recall the primary sources of useful content.
\end{abstract}

\section{Categories and Subject Descriptors}

K.3.3 Computer Uses in Education - Collaborative learning, Computer-assisted instruction, Distance Learning.

\section{General Terms}

Management, Measurement, Design, Human Factors,

\section{Keywords}

Digital Library, User study

\section{INTRODUCTION}

Knowing how digital libraries and their contents are used is inextricably tied to a library's ability to sustain itself, grow its services and meet its users' needs. The number of digital libraries is growing; for example, the National Science Digital Library (NSDL) now holds over 550 collections, doubling in size within a two to three year period. Institutional repository projects and the Open CourseWare movement have also made seen significant growth. At the same time critics such as Robert Zemsky [1] claim that digital library projects as a part of the higher education Elearning movement have not reached their potential because of the relative few number of faculty and instructors who use them in their academic work. This perception may be particularly pertinent in terms of those digital libraries such as the NSDL that focus on making accessible digital educational or curricular materials. Given the cost of the development and maintenance of digital libraries, questions about users and how they actually use materials, have become central [2].

We report the results of exploratory research regarding use and non-use of the NSDL that will culminate in a national survey of STEM instructors. This research delves more deeply into the barriers to use most frequently mentioned in the literature such as time and resource constraints, lack of access to high quality materials, lack of adaptability of the materials themselves, and intellectual property $[2,3]$. To date, research regarding barriers to use of digital libraries has been relatively small in scale, focusing on users of individual libraries or small samples of non-users within a specific discipline $[4,5]$. In this study, we focused on characterizing instructors' work patterns in relation to digital learning and teaching materials and what makes an online digital library useful. We report here on several of themes emerging from this phase of the research.

\section{METHOD}

For comparative purposes, the research methods employed resemble those used in the Center for Studies in Higher Education study of use of digital learning materials by instructors in the humanities and social sciences [2]. In this research, focus groups were conducted to identify and refine questions used in a subsequent online survey of 4,500 faculty members from California community and four-year public and private institutions. These procedures were adapted for the audience of our research, instructors in STEM education; the resulting survey will be administered nationally.

Because of the diverse nature of colleges and universities in the United States, 11 focus groups (total of 60 participants) were conducted at: one research university, one community college, four primarily teaching universities, two historically black colleges, one liberal arts college and two at the MERLOT International Conference. Grounded theory procedures [6] guided the analysis of the focus group data allowing the underlying themes to emerge. For example, lack of time is one of the most frequently mentioned reasons instructors do not search for, nor integrate online learning materials into their courses. However, instructors in the focus groups described spending numerous hours searching for content as specific as one 'perfect' image, only to settle for something that was 'good enough'. This result suggests layers of meanings behind 'lack of time'. While searching for materials can be time consuming, instructors are willing to make trade-offs taking the necessary time to find the materials that met their goals, student needs, or were easy to use. 
Of particular interest to the analysis were questions relating to instructors' work patterns such as: how do instructors use the Internet to search for materials online, which Internet resources are preferred, and when and why do they look for online learning materials?

\section{RESULTS - EMERGING THEMES 3.1 Search Goals and Behavior}

Borgman et. al. reports that faculty members in geography conduct logical, methodological searches for online teaching or learning materials much like they do when conducting research in their disciplines [5]. They also reported that the faculty members in this study were more able to articulate search strategies for research purposes than for teaching purposes. This factor is important when studying all STEM instructors and when considering potential or non-users of digital libraries. The faculty members in the Borgman study were located at a research institution and were innovators both in terms of use of technology and in terms of teaching practice. In contrast, the population of STEM instructors in our focus groups included non-users or potential users from a variety of colleges and universities who were not necessarily innovators. And, unlike Borgman's sample, these instructors reported very idiosyncratic search practices ranging from almost random to more systematic patterns combining searching and browsing behaviors.

Participants from the focus groups relied heavily on trusted sources and personal networks for finding materials. When asked to describe how they search for materials they used in a class, they reported starting with a website attributed to a known instructor or websites associated with established textbooks or governmental agencies. When describing Internet searching, they inevitably started with Google. Upon finding a resource they liked here, it became the springboard, using it to explore the resources that were linked to the original resource. In all cases, Google was the primary starting point for searching. Interestingly, involvement in one digital library did not seem to translate into knowing about other digital libraries or using them, for even the participants in the MERLOT digital library relied heavily on Google searches.

\subsection{Differentiation of Digital Libraries}

Few of the focus group participants distinguished between the sources for online resources, instead lumping all web resources together as being equally useful. Starting a search with Google obscured the types of resources returned since Google results are not differentiated, i.e., web pages, digital libraries, or images are all described similarly, so each result must be visited and explored by the user. Time spent in the search activity combined with the large number of results and the lack of efficient search strategies resulted in users settling for materials that were 'good enough'. Participants recalled the types of materials and how they used them in a classroom but usually were not conscious of having used a digital library or collection to find them.

\subsection{Characteristics of Useful Collections}

Participants searched for materials mainly to make lectures or assignments more relevant to their students. They described seeking images, animations or simulations and 'real world' data or data sets, in short: materials to add to lectures. Instructors also looked to find examples of how courses were organized or presented. Expectations of colleagues and students motivated instructors to search for online learning materials as did dissatisfaction with textbooks and their CD or online supplements. When turning to colleagues as resources, instructors turned to those who taught similar courses or had professional reputations as innovators. Instructors noted that they went to a particular collection over Google only when they knew exactly the site or source they wanted, had knowledge of what a site offered or wanted vetted resources for student use.

Instructors searched most frequently for real world data, data sets and examples and did so with little time to spare. They reported looking for real world data within days but more usually hours before they needed it. The immediacy of the web, and most particularly Google, affected their ability to do this. Most instructors noted that they did not go directly to a digital library site to find this kind of material, nor did they search specifically for materials related to professional development and teaching.

\section{IMPLICATIONS}

These preliminary findings provide insight into how, why and what kinds of resources are useful to STEM instructors who are either not currently users of the NSDL or another educational digital library or who are not cognizant that they are using them. It has given us insight into the relationship between Google, searching behaviors and how instructors view digital libraries as resources within their profession. While these preliminary results will inform us as we develop the national survey to be administered to STEM instructors, the implications are also useful for NSDL collections as they seek effective strategies to increase the value of their collections for their users and in marketing and sustaining their collections.

\section{ACKNOWLEDGMENTS}

This work was funded by the National Science Foundation, Grant \# DUE 435398.

\section{REFERENCES}

[1] Zemsky, R., \& Massy, W. (2004). Thwarted innovation: What happened to e-learning and why: The Learning Alliance

[2] Harley, D. et. al. The Use of Digital Resources in Humanities and Social Science Undergraduate Education. Center for Studies in Higher Education. Available: http://digitalresourcestudy.berkeley.edu/. October 2004.

[3] Gibbs, E.J., Major, C.H., \& Wright, V.H. Faculty perception of the costs and benefits of instructional technology: Implications for faculty work. The Journal of Faculty Development. V19 (2), pp. 77 - 88. 2004.

[4] Manduca, C.A., S. Fox, E. Iverson, F. McMartin (2005) Influencing User Behavior through Digital Library Design D-Lib, May, 2005.

[5] Borgman, C. et al. How geography professors select materials for classroom lectures: implications for the design of digital libraries. Proceedings of the 4th ACM/IEEE-CS Joint Conference on Digital Libraries. ACM Press, New York, NY, 2004, pp. 179-185.

[6] Glaser, B \& Strauss A. Discovery of Grounded Theory: Strategies for Qualitative Research. Aldine, Chicago, IL, 1967. 
